\title{
Induction of Phase II Enzymes Glutathione-S-Transferase and NADPH: Quinone Oxydoreductase 1 with Novel Sulforaphane Derivatives in Human Keratinocytes: Evaluation of the Intracellular GSH Level
}

\author{
Sohely Sikdar, Benjamin Lallemand, Jacques Dubois \\ Laboratoire de Chimie BioAnalytique, Toxicologie et Chimie Physique Appliquée, Faculté de Pharmacie, \\ Université Libre de Bruxelles (ULB), Boulevard du Triomphe, Brussels, Belgium \\ Email: ssikdar@ulb.ac. be
}

Received 8 August 2014; revised 5 September 2014; accepted 16 September 2014

Copyright (C) 2014 by authors and Scientific Research Publishing Inc.

This work is licensed under the Creative Commons Attribution International License (CC BY).

http://creativecommons. org/licenses/by/4.0/

(c) (i) Open Access

\begin{abstract}
Phase II enzymes including NADPH: Quinone Oxydoreductase 1 (NQO1) and Glutathione-S-Transferase (GST) represents a major and natural cellular protection system against deleterious environmental factors which cause skin damages. Sulforaphane is one of the most popular isothiocyanates found in cruciferous vegetables and known for its cytoprotective effects by inducing Phase II enzymes. Five novel sulforaphane derivatives were synthetized and tested for their activity on NQ01 and GST induction as well as for their effect on total GSH intracellular level using colorimetric assays on human keratinocytes cell line (HaCat). As sulforaphane and the synthetized components showed variable toxicity after their evaluation by means of in vitro cytotoxicity (MTT test), cells were treated at a concentration of $5 \mu \mathrm{M}$ during 48 hours. The results showed that the addition products of sulforaphane decreased cytotoxity but none of those derivatives had a better effect than referenced sulforaphane on Phase II enzymes. It seems that the isothiacyanate function remains important for the sulforaphane activity.
\end{abstract}

\section{Keywords}

Phase 2, Glutathione, Sulforaphane, Keratinocytes 


\section{Introduction}

Human skin is constantly exposed to environmental harmful factors such as heavy metals, xenobiotics and UV radiations. These factors cause damages at many molecular levels. DNA, membrane lipids and proteins are more likely to undergo these damages leading to skin diseases and cancer [1]. Fortunately, nature has given to mammalian cells natural protection mechanisms. Detoxification through Phase I and Phase II enzymes is the most important and powerful pathway to skip environmental damages. Phase I reactions may occur by oxidation, reduction, hydrolysis, cyclization and decyclization, addition of oxygen or removal of hydrogen, while Phase II reactions, known as conjugation reactions, are usually detoxicating in nature, and may involve the interactions of the polar functional groups of Phase I metabolites [2].

Phase II enzymes, which are widely distributed in mammalian cells and tissue, include the following: NADPH: quinone oxydoreductase 1 (NQO1), which promotes obligatory two-electron reductions of quinines [3], preventing their participation in oxidative cycling and the depletion of intracellular glutathione (GSH); glutathione-S-transferase (GST), which conjugates hydrophobic electrophiles with GSH [4] [5]. This detoxifying system is widely described in hepatic cell lines where its function is the most efficient [6]. However the impairment of detoxification systems with ageing through loss of the Nrf2 signaling pathway has been yet demonstrated [7] [8] and Phase II enzymes has been proven to be highly inducible in human keratinocytes [9] [10].

Glutathione (GSH) is a tripeptide with a gamma peptide linkage between the amine group of cysteine and the carboxyl group of the glutamate side-chain. Glutathione exists in reduced (GSH) and oxidized (GSSG) states [11]. In the reduced state, the thiol group of cysteine donates an electron to other unstable molecules, such as reactive oxygen species and then becomes reactive itself, but readily reacts with another reactive glutathione to form glutathione disulfide (GSSG). It is a major endogenous cellular antioxidant, participating directly in the neutralization of free radicals and reactive oxygen species. GSH is known as a substrate in both conjugation reactions and reduction reactions, catalyzed by glutathione-S-transferase (GST) enzymes in cytosol, microsomes and mitochondria [11].

Members of the cruciferous vegetable family (Brassica oleracea), which includes broccoli, Brussels sprouts, cauliflower and cabbage, accumulate significant concentrations of glucosinolates which are metabolized in vivo to biologically active isothiocyanates (ITCs) [12]. The ITC sulforaphane (1), which is derived from glucoraphanin, has garnered particular interest as an indirect antioxidant due to its extraordinary ability to induce expression of several enzymes via the KEAP1/Nrf2/ARE pathway [13]. Nrf2/ARE gene products are typically characterized as Phase II detoxification enzymes [14] [15]. Sulforaphane is small molecule with the highly reactive isothiocyanate functionality that covalently modifies cysteine residues in proteins.

A recent study [13] showed a capacity of sulforaphane isoselenocyanate analog to enhance GSH level through Nrf2 signaling pathway more efficiently than sulforaphane itself. This offered a hint for the syntheses of novel sulforaphane derivatives that can be easily produced at lower cost and present higher efficacy on GSH level and Phase II enzymes activity as both are Nrf2-dependant. Previously, sulforaphane was presented as an inducer of GST in mouse skin [16].

In the present study, we brought to light the potent induction of Phase II enzymes NQO1 and GST by novel sulforaphane derivatives and we evaluated the intracellular GSH level with these compounds.

\section{Materials and Methods}

\subsection{Purity and Stability}

The purity of each synthesized compound was verified by means of NMR ${ }^{1} \mathrm{H}$ and HPLC-UV analysis and reached a level > 95\%. HPLC analysis was performed with an Agilent 1120 series HPLC system (Agilent, Diegem, Belgium). The chromatographic system was an RX-C18 (5 $\mu \mathrm{m})(4.6 \mathrm{~mm} \times 250 \mathrm{~mm})$ (Agilent, Diegem, Belgium) or a Discovery ${ }^{\circledR C} 18(5 \mu \mathrm{m})(4.6 \mathrm{~mm} \times 150 \mathrm{~mm})$ (Supelco, Bornem, Belgium) using the same mobile phase for all compounds: ACN-water 50:50 for $10 \mathrm{~min}$. The purity given was measured by this HPLC method at their maximum wavelength absorbance $(305 \mathrm{~nm})$. U. V. spectra were recorded on a biochrom WPA biowave II (Analis, Namur, Belgium).

\subsection{Pharmacological Assays}

\subsubsection{General}

HaCat cell line was obtained from Cell Line Service (Eppelheim, Germany); DMEM F-12 and fetal bovine se- 
rum were obtained from Life Technologies (Gent, Belgium); DTNB, NADPH, GSH reductase, CDNB (1-chloro2,4-dinitrobenzene), MTT, NADP, bovine serum albumine, FAD, glucose-6-phosphate, baker's yeast glucose-6phosphate deshydrogenase, menadione, Tween 20, Tris Base, crystal violet were obtained from Sigma-Aldrich (Bornem, Belgium); DMSO was obtained from VWR (Leuven, Belgium); microtiter wells and T-25 flasks were purchased from Sarstedt (Nümbrecht, Germany).

\subsubsection{Culture and Treatment}

HaCat cells were plated at a density of 300,000 cells/T-25 flasks in 7 ml of DMEM F-12 supplemented with $10 \%$ fetal bovine serum for GST and GSH assays, or at 50,000/ml in microtiter plates for NQO1 assay. The cells were grown for $24 \mathrm{~h}$ in a humidified incubator in $5 \% \mathrm{CO}_{2}$ at $37^{\circ} \mathrm{C}$. They were then treated with $5 \mu \mathrm{M}$ of each compound diluted in cell culture medium for 24 hours. For GST and GSH assays, cells were incubated for an additional $24 \mathrm{~h}$ after which, medium was replaced by fresh $5 \mu \mathrm{M}$ solutions.

\subsubsection{Determination of in Vitro Growth Inhibition}

HaCat viability was determined using a colorimetric MTT (3-[4,5-dimethylthiazol-2yl-diphenyl tetrazolium bromide) assay as detailed previously [17]. For MTT test, HaCat cells were plated at a density of 50,000 cells/ml in DMEM F-12 media and incubated for $24 \mathrm{~h}$ at $37^{\circ} \mathrm{C}$. They were then treated with test compounds at concentrations from 0.1 to $100 \mu \mathrm{M}$ and incubated for $72 \mathrm{~h}$ at $37^{\circ} \mathrm{C}$. Each experimental condition was performed in six replicates.

\subsubsection{Assay of Glutathione-S-Transferase (GST)}

A colorimetric assay using CDNB was performed to measure the GST activity. The reaction mixture consisted of $100 \mathrm{mM}$ phosphate buffer saline pH 7.5; $1 \mathrm{mM}$ GSH reduced; $1 \mathrm{mM}$ CDNB in $2 \%$ ethanol. $280 \mu \mathrm{l}$ of this mixture was added to $20 \mu \mathrm{l}$ of lysate. Upon conjugation of the thiol group of glutathione to the CDNB substrate, CDNB-GSH conjugation (formation of DNP-glutathione conjugate [DNP-SG] via nucleophilic displacement of $\mathrm{Cl}$ with the GSH-thiol) was monitored spectrophotometrically at $340 \mathrm{~nm}$ for $5 \mathrm{~min}$. The experiment was carried out in triplicate.

\subsubsection{Assay of NADPH: Quinone Oxydoreductase 1 (NQ01)}

Prochaska and Santamaria's method was used for the measurement of NQO1 [18]. Each experimental condition was carried out in six replicates and the experiment in triplicate $(n=18)$.

\subsubsection{Assay of Total Reduced Glutathione Level (GSH)}

A colorimetric assay using Ellman's reagent was used for this test. The assay employs a kinetic enzymatic recycling assay based on the oxidation of GSH by 5,5'-dithiobis(2-nitrobenzoic acid) [DTNB] to measure the total glutathione (tGSH) content of biological samples. After $24 \mathrm{~h}$ of treatment with the test compounds, cells were rinced twice with PBS, sonicated for $30 \mathrm{~min}$ and scrapped until detachment. $500 \mu \mathrm{l}$ of the lysate was centrifuged for $5 \mathrm{~min}$ at $400 \mathrm{rpm}$. $100 \mu \mathrm{l}$ of supernatant from each sample were used to perform the test and put in a 96-wells plate. $100 \mu \mathrm{l}$ of DTNB $1.26 \mathrm{mM}$ and $50 \mu \mathrm{l}$ of GSH reductase $2.5 \mathrm{U} / \mathrm{ml}$ were added to the test samples. The plate was incubated 5 min at room temperature before adding $50 \mu$ of NADP $0.72 \mathrm{mM}$ to each sample. The absorbance was monitored directly after at $340 \mathrm{~nm}$ for 5 min (recording 10 time points) with an automated spectrophotometer Labsystemsi EMS Reader MF (Ramat-Gan, Israel). The experiment was carried out in triplicate.

\subsection{Statistical Analysis}

Data are expressed as the means \pm SDev. Data obtained from independent groups (2-6) were compared to 1 by Mann-Whitney U tests. The statistical analyses were performed using Statistica software (Statsoft, Tulsa, USA).

\section{Results and Discussion}

In order to lighten up the essential role of each chemical function of sulforaphane in its chemoprotective effect, we modulated various functions and evaluated the activity of each new compound. The syntheses of these derivatives were reported in the patent WO 2012010644 A1 and all newly derivatives were structurally represented in Table 1. 
Table 1. Illustration of the chemical structure studied and in vitro growth inhibitory activity induced by treatment with sulforaphane and its five derivatives.

\begin{tabular}{|c|c|c|c|c|c|}
\hline \multicolumn{5}{|c|}{ Compounds R-Y-( $\left(\mathrm{CH}_{2}\right)_{n}-\mathrm{Z}$} & \multirow{2}{*}{$\begin{array}{c}\text { IC }_{50} \text { in vitro }(\mu \mathrm{M})^{a} \\
\text { HaCat cell line }\end{array}$} \\
\hline$\#$ & $\mathrm{R}$ & $\mathrm{Y}$ & $\mathrm{n}$ & Z & \\
\hline 1 & $\mathrm{CH}_{3}$ & SO & 4 & NCS & 9 \\
\hline 2 & & SO & 4 & NCS & 5 \\
\hline 3 & $\mathrm{CH}_{3}$ & $\mathrm{CO}$ & 4 & NCS & 2 \\
\hline 4 & $\mathrm{CH}_{3}$ & $\mathrm{CO}$ & 4 & & 95 \\
\hline 5 & $\mathrm{CH}_{3}$ & SO & 4 & & $>100$ \\
\hline 6 & $\mathrm{CH}_{3}$ & SO & 4 & & 27 \\
\hline
\end{tabular}

${ }^{\mathrm{a}}$ The $\mathrm{IC}_{50}$ in vitro cytotoxic concentrations of all compounds were determined with a MTT colorimetric assay after three days of culturing the HaCatcells (Cell Line Service; Eppelheim, Germany) with the respective drugs. Six data points were available for each concentration tested and nine concentrations (from 0.01 to $100 \mu \mathrm{M}$ ) were available for each cell line.

After verifying the purity and stability of the newly synthesized compounds by RP-HPLC, the $\mathrm{IC}_{50}$ in vitro cytotoxic concentrations of all derivatives and sulforaphane (1) were determined with a MTT colorimetric assay [17] on HaCat cell line after three days of culturing the cells with the respective drugs (Table 1). Results showed that the replacement of the ITC function (4-6) decreases cytotoxicity on HaCat cell lines and displays growth inhibitory concentration ( $\mathrm{IC}_{50}$ ) between 27 and $>100 \mu \mathrm{M}$ comparing to ITC function which is more cytotoxic with $\mathrm{IC}_{50}$ values between 2 and $9 \mu \mathrm{M}(\mathbf{1}-\mathbf{3})$.

All results are shown in Figure 1. Results on NQO1 show that sulforaphane (1), as described in the literature [19], is a good candidate for NQO1 induction with a maximal induction of $2.4 \pm 0.3$ at $5 \mu \mathrm{M}$ in our test. The isothiocyanates derivatives substituted by addition products (4-6) significantly decrease the efficacy of the compound at $5 \mu \mathrm{M}$ with respective maximal induction values of $1.8 \pm 0.2,0.9 \pm 0.1$ and $1.3 \pm 0.1$ comparing to control assay. The replacement of the methyl group with a phenyl group (2) has no significant effect while the replacement of the sulfinyl group with a carbonyl group (3) induces a significant decrease of the NQO1 induction.

The total GSH level kinetic assay was performed in order to evaluate the induction of GSH production by each compound at $5 \mu \mathrm{M}$ comparing to an untreated control assay. We consider the induction as the ratio between assay slope and control slope. All of the derivatives tested never beat the high level of GSH retrieving in the cell treated by sulforaphane (1), i.e. $2.5 \pm 0.3$.

The glutathione S-transferase (GST) activity assay was then applied to these derivatives at the same concentration of $5 \mu \mathrm{M}$ in order to compare their activity (Figure 1). Compound 2 shows significantly better effect on GST activity than reference molecule sulforaphane (1) after replacement of the methyl group with a phenyl group. However, while replacing sulfinyl by carbonyl group, compounds $\mathbf{3}$ and $\mathbf{4}$ show closely similar effect to sulforaphane. However, when ITC function is substituted by addition products (4-6), the GST activity is weaker.

In summary, the substitution of the isothiocyanate group from sulforaphane ( $\mathrm{Z}$ position, Table 1$)$ decreases its toxicity on HaCat cell line but also generally decreases the efficacy on both GST and NQO1 induction. We see a significant higher effect on GST activity when the methyl group is replaced with a phenyl group, allowing the hypothesis that sterically hindered molecules are necessary to specifically induce GST. Indeed, this improvement is not correlated with the GSH level or NQO1 activity. In accordance with all the results, isothiocyanate 


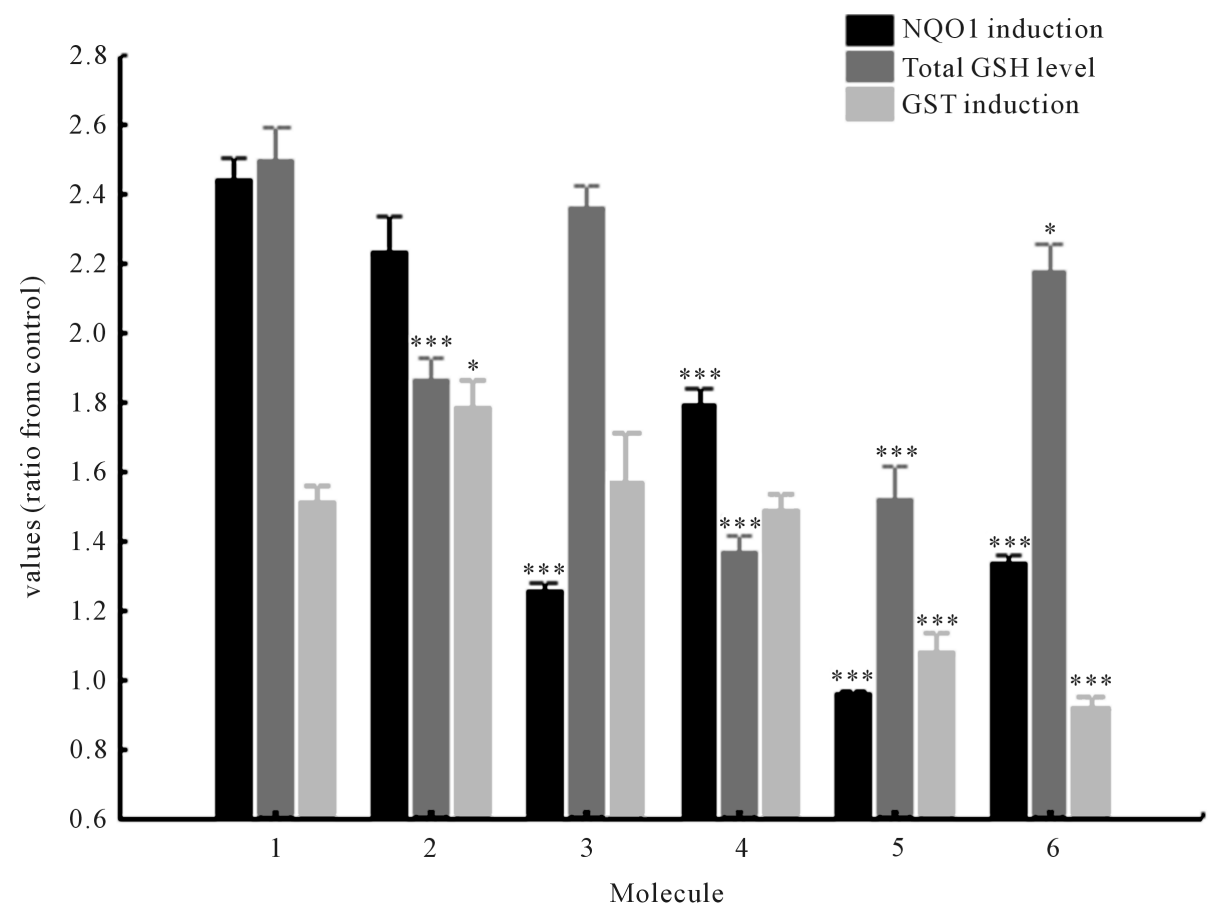

Figure 1. Determination of the induction of Phase II enzymes NQO1 and GST by sulforaphane derivatives and evaluation of the intracellular GSH level. All tested compounds were assessed at the same concentration of $5 \mu \mathrm{M}$ on HaCat cell line. The induction value was determined by means of assay values versus untreated control. The GSH level was evaluated by recording 10 time points absorbance for 5 minutes followed by comparison of the slope between the assay and the control. Each experimental condition was performed in triplicate and the data are presented as mean \pm SD values. $*$ : $\mathrm{p}<0.01 ;{ }^{* *}: \mathrm{p}<0.005 ; * * * \mathrm{p}<0.0005$

group seems to be essential to observe a significant effect of sulforaphane and its derivatives on both enzymes and GSH level.

\section{Acknowledgements}

This work was supported by Auriga International s. a. and La Région Wallonne.

\section{References}

[1] Kwak, M.-K., Egner, P.A., Dolan, P.M., Ramos-Gomez, M., Groopman, J.D., Itoh, K., Yamamoto, M. and Kensler, T.W. (2001) Role of Phase 2 Enzyme Induction in Chemoprotection by Dithioethiones. Mutation Research, 480-481, 305-315. http://dx.doi.org/10.1016/S0027-5107(01)00190-7

[2] Iyanagi, T. (2007) Molecular Mechanism of Phase I and Phase II Drug-Metabolizing Enzymes: Implications for Detoxification. International Review of Cytology, 260, 35-112. http://dx.doi.org/10.1016/S0074-7696(06)60002-8

[3] Nolan, K.A. Timson, D.J., Stratford, I.J. and Bryce, R.A. (2006) In Silico Identification and Biochemical Characterization of Novel Inhibitors of NQO1. Bioorganic \& Medicinal Chemistry Letters, 16, 6246-6254. http://dx.doi.org/10.1016/j.bmcl.2006.09.015

[4] Dinkova-Kostova, A.T. and Talalay, P. (2010) NAD(P)H:Quinine Acceptor Oxidoreductase 1 (NQO1), a Multifunctional Antioxidant Enzyme and Exceptionally Versatile Cytoprotector. Archives of Biochemistry and Biophysics, 501, 116-123. http://dx.doi.org/10.1016/j.abb.2010.03.019

[5] Jancova, P., Anzenbacher, P. and Anzenbacherova, E. (2001) Phase II Drug Metabolizing Enzymes. Biomed. Medical Faculty University Palacky Olomouc Czech Republic, 154, 103-116. http://dx.doi.org/10.5507/bp.2010.017

[6] Lu, S.C. (1999) Regulation of Hepatic Glutathione Synthesis: Current Concepts and Controversies. The FASEB Journal, 13, 1169-1183.

[7] Suh, J.H., Shenvi, S.V., Dixon, B.M., Liu, H., Jaiswal, A.K., Liu, R.M. and Hagen, T.M. (2004) Decline in Transcrip- 
tional Activity of Nrf2 Causes Age-Related Loss of Glutathione Synthesis, Which Is Reversible with Lipoic Acid. Proceedings of the National Academy of Sciences of the United States of America, 101, 3381-3386. http://dx.doi.org/10.1073/pnas.0400282101

[8] Shenvi, S.V., Smith, E. and Hagen, T.M. (2012) Identification of Age-Specific Nrf2 Binding to a Novel Antioxidant Response Element Locus in the Gclc Promoter: A Compensatory Means for the Loss of Glutathione Synthetic Capacity in the Aging Rat Liver. Aging Cell, 11, 297-304. http://dx.doi.org/10.1111/j.1474-9726.2011.00788.x

[9] Dinkova-Kostova, A.T., Holtzclaw, W.D. and Kensler, T.W. (2005) The Role of Keap1 in Cellular Protective Responses. Chemical Research in Toxicology, 18, 1779-1791. http://dx.doi.org/10.1021/tx050217c

[10] Wakabayashi, N., Dinkova-Kostova, A.T., Holtzclaw, W.D., Kang, M.I., Kobayashi, A., Yamamoto, M., Kensler, T. W. and Talalay, P. (2004) Protection against Electrophile and Oxidant Stress by Induction of the Phase 2 Response: Fate of Cysteine of the Keap 1 Sensor Modified by Inducers. Proceedings of the National Academy of Sciences of the United States of America, 101, 2040-2045. http://dx.doi.org/10.1073/pnas.0307301101

[11] Owen, J.B. and Butterfield, D.A. (2010) Measurement of Oxidized/Reduced Glutathione Ratio. Methods in Molecular Biology, 648, 269-277. http://dx.doi.org/10.1007/978-1-60761-756-3_18

[12] Shapiro, T.A., Fahey, J.W., Wade, K.L., Stephenson, K.K. and Talalay, P. (2001) Chemoprotective Glucosinolates and Isothiocyanates of Broccoli Sprouts: Metabolism and Excretion in Humans. Cancer Epidemiology, Biomarkers \& Prevention, 10, 501-508.

[13] Emmert, S.W., Desai, D., Amin, S. and Richie Jr., J.P. (2010) Enhanced Nrf2-Dependant Induction of Glutathione in Mouse Embryonic Fibroblasts by Isoselenocyanate Analog of Sulforaphane. Bioorganic \& Medicinal Chemistry Letters, 20, 2675-2679. http://dx.doi.org/10.1016/j.bmcl.2010.01.044

[14] Fahey, J.W. and Talalay, P. (1999) Antioxidant Functions of Sulforaphane: A Potent Inducer of Phase II Detoxication Enzymes. Food and Chemical Toxicology, 37, 973-979. http://dx.doi.org/10.1016/S0278-6915(99)00082-4

[15] Dinkova-Kostova, A.T., Fahey, J.W., Wade, K.L., Jenkins, S.N., Shapiro, T.A., Fuchs, E.J., Kerns, M.L. and Talalay, P. (2007) Induction of the Phase 2 Response in Mouse and Human Skin by Sulforaphane-Containing Broccoli Sprout Extracts. Cancer Epidemiology, Biomarkers \& Prevention, 16, 847-851. http://dx.doi.org/10.1158/1055-9965.EPI-06-0934

[16] Abel, E.L., Boulware, S., Fields, T., Mclvor, E., Powell, K.L., DiGiovanni, J., Vasquez, K.M. and MacLeod, M.C. (2013) Sulforaphane Induces Phase II Detoxication Enzymes in Mouse Skin and Prevents Mutagenesis Induced by a Mustard Gas Analog. Toxicology and Applied Pharmacology, 266, 439-442. http://dx.doi.org/10.1016/j.taap.2012.11.020

[17] Lallemand, B., Chaix, F., Bury, M., Bruyère, C., Ghostin, J., Becker, J.P., Delporte, C., Gelbcke, M., Mathieu, V., Dubois, J., Prévost, M., Jabin, I. and Kiss, R. (2011) N-(2-(3[3,5-bis(trifluoromethyl)phényl]ureido)ethyl)-Glycyrrhetinamide (6b): A Novel Anticancer Glycyrrhetinic Acid Derivative that Targets the Proteasome and Displays AntiKinase Activity. Journal of Medicinal Chemistry, 54, 6501-6513. http://dx.doi.org/10.1021/jm200285z

[18] Prochaska, H.J. and Santamaria, A.B. (1988) Direct Measurement of NAD(P)H: Quinone Reductase from Cells Cultured in Microtiter Wells: A Screening Assay for Anticarcinogenic Enzyme Inducers. Analytical Biochemistry, 169, 328-336.

[19] Ahn, Y.H., Hwang, Y., Liu, H., Wang, X.J., Zhang, Y., Stephenson, K.K., Boronina, T.N., Cole, R.N., DinkovaKostova, A.T., Talalay, P. and Cole, P.A. (2010) Electrophilic Tuning of the Chemoprotective Natural Product Sulforaphane. Proceedings of the National Academy of Sciences of the United States of America, 107, 9590-9595. http://dx.doi.org/10.1073/pnas.1004104107 


\section{Abbreviations}

NQO1: Quinone oxidoreductase-1

GST: Glutathione-S-Transferase

UV: Ultraviolet

DNA: Desoxyribonucleic acid

Nrf-2: Nuclear factor (erythroid-derived 2)-like 2

GSH: Glutathione reduced

GSSG: Glutathione oxidized

ITC: Isothiocyanate

KEAP-1: Kelch like-ECH-associated protein 1

ARE: Antioxidant response element

HPLC: High performance liquid chromatography

DMEM: Dubelcco's modified Eagle medium

DTNB: Dithionitrobenzene

NADP: Nicotinamide adénine dinucléotide phosphate

NADPH: Nicotinamide adénine dinucléotide phosphate reduced

CDNB: 1-chloro-2, 4-dinitrobenzene

FAD: Flavine adénine dinucléotide 
Scientific Research Publishing (SCIRP) is one of the largest Open Access journal publishers. It is currently publishing more than 200 open access, online, peer-reviewed journals covering a wide range of academic disciplines. SCIRP serves the worldwide academic communities and contributes to the progress and application of science with its publication.

Other selected journals from SCIRP are listed as below. Submit your manuscript to us via either submit@scirp.org or Online Submission Portal.
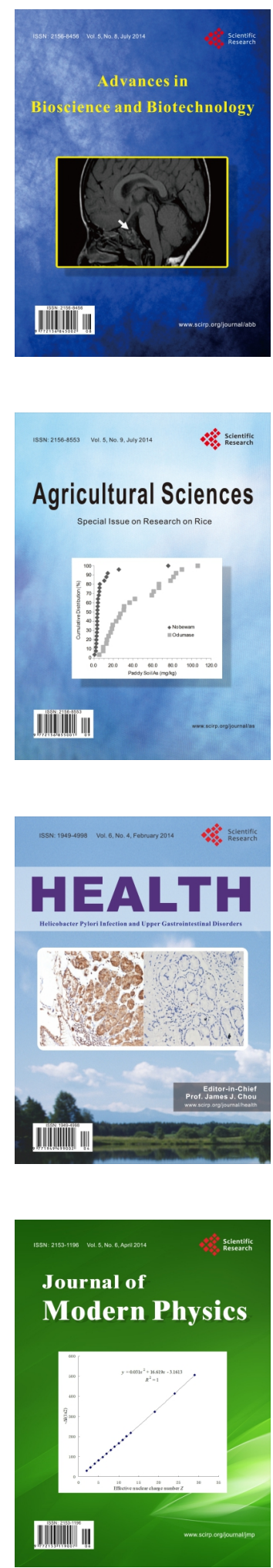
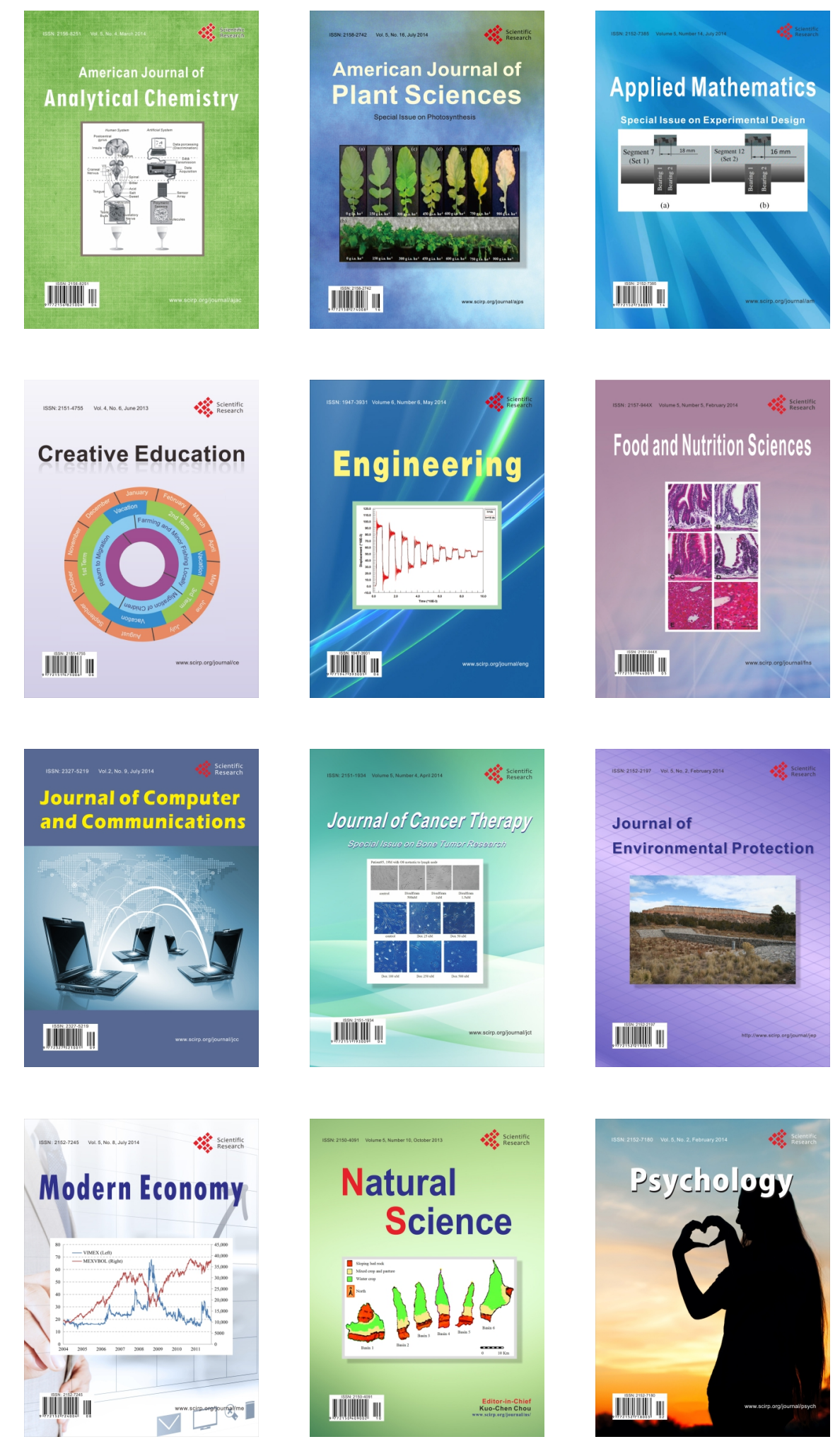